\title{
Association of EGFR mutations with low BRCA1 gene expression in non-small cell lung cancer
}

\author{
HUI LI, LING XIE and REN-SENG LAI \\ Department of Pathology, The Affiliated Hospital of Nanjing University \\ of Traditional Chinese Medicine (TCM), Nanjing, P.R. China
}

Received June 20, 2012; Accepted September 12, 2012

DOI: $10.3892 / \mathrm{mco} .2012 .34$

\begin{abstract}
Clinical studies suggest that the mRNA expression level of excision repair cross complementing group 1 gene (ERCC1) is associated with epidermal growth factor receptor (EGFR) mutation and breast cancer susceptibility 1 gene (BRCA1) mRNA expression in non-small cell lung cancer (NSCLC). In this study, the correlation between EGFR mutation status and ERCC1 and BRCA1 gene expression in Chinese NSCLC patients was examined. Real-time polymerase chain reaction (PCR) and direct sequencing were used to detect mRNA expression levels and EGFR mutation status, respectively in microdissected formalin-fixed paraffinembedded non-small cell lung cancer tissues. EGFR mutations were detected in $27 / 103$ patients $(26.2 \%)$ and were found to be gender-related $(\mathrm{P}=0.001)$. The BRCA1 mRNA expression level was associated with histology, while there was no association with ERCC1. For the EGFR mutant-type, a high BRCA1 gene expression was detected in 2 cases $(20.0 \%)$ and a low expression in 8 cases $(80.0 \%)$, while for EGFR wild-type, a high BRCA1 gene expression was detected in 20 cases $(43.5 \%)$ and a low expression in 26 cases $(56.5 \%)$. There was no difference in the one-year survival period, according to results obtained for either the ERCC1 or BRCA1 mRNA expression levels. EGFR mutations in NSCLC samples are more likely to express low ERCC1 and BRCA1 mRNA levels. In these latter samples, a statistically significant difference was observed. However, to examine their correlation and clinical outcomes, additional studies are required.
\end{abstract}

Correspondence to: Professor Ren-Sheng Lai, Department of Pathology, The Affiliated Hospital of Nanjing University of Traditional Chinese Medicine (TCM), Nanjing 210029, P.R. China E-mail: lairensheng@163.com

Key words: non-small cell lung cancer, excision repair cross complementing group 1 gene, breast cancer susceptibility 1 gene, epidermal growth factor receptor, direct sequencing, real-time polymerase chain reaction

\section{Introduction}

Non-small cell lung cancer (NSCLC) is one of the most common malignant tumors. Platinum-based chemotherapy is the first-line treatment of advanced NSCLC. Studies showed that advanced NSCLC patients with a high expression of excision repair cross complementing group 1 gene (ERCC1) were resistant to cisplatin, resulting in the failure of chemotherapy treatment (1). By contrast, a low expression of ERCC1 mRNA levels indicated sensitivity to platinum (2). Moreover, preclinical and clinical studies have reported that breast cancer susceptibility 1 gene (BRCA1) mRNA expression was negatively correlated with cisplatin sensitivity $(3,4)$. However, Iressa ${ }^{\circledR}$, Tarceva ${ }^{\circledR}$ and other epidermal growth factor receptor (EGFR) tyrosine kinase inhibitors (TKI) are the most promising target treatment approach, while EGFR mutation is the indicator for the use of these drugs. Clinical studies also showed patients with EGFR mutations to have a better response to platinum (5). Additionally, recent studies have demonstrated that EGFR mutations in NSCLC samples were correlated with low ERCC1 mRNA levels (6). Therefore, a study on the correlation between EGFR mutations and ERCC1 and BRCA1 gene expression in a Chinese population was conducted.

\section{Materials and methods}

Subjects. A total of 103 Chinese patients were enrolled between March, 2007 and November, 2010. Of those, 62 were male and 41 female (median age, 41; range, 31-80 years). The patients were diagnosed based on the 2008 World Health Organization (WHO) classification. None of the patients received Iressa or chemotherapy prior to surgery. The patients were treated with platinum-based chemotherapy subsequent to surgery.

RNA extraction and real-time quantitative PCR (RT-qPCR) reaction for $m R N A$ expression. Total RNA was isolated from paraffin-embedded NSCLC tissues using Tissue RNA kit (RNase-free FFPE kit; Qiagen, Valencia, CA, USA), after written informed consent was obtained from the participants. RT reaction $(10 \mu \mathrm{l})$ was performed using: $1 \mu \mathrm{l}$ gDNA, $6 \mu \mathrm{l}$ RNA + DEPC $\mathrm{H}_{2} \mathrm{O}$, at $42^{\circ} \mathrm{C}$ for $2 \mathrm{~min}, 0.5 \mu \mathrm{l}$ primer $(10 \mathrm{nmol} / \mu \mathrm{l}), 0.5 \mu \mathrm{l}$ RTase and $2 \mu \mathrm{l}$ buffer at $42^{\circ} \mathrm{C} 30 \mathrm{~min}$, then $95^{\circ} \mathrm{C}$ for $5 \mathrm{~min}$, carried out by SYBR-Green real-time PCR with an ABI 7900HT Fast Real-Time PCR system (Applied 
Table I. Correlation between ERCC1 mRNA expression and the clinicopathological characteristics of patients with NSCLC.

\begin{tabular}{|c|c|c|c|c|c|}
\hline Clinicopathological parameters & No. cases & High expression & Low expression & $\chi^{2}$ & P-value \\
\hline \multicolumn{6}{|l|}{ Gender } \\
\hline Male & 62 & 34 & 27 & 1.998 & 0.157 \\
\hline Female & 41 & 17 & 24 & & \\
\hline \multicolumn{6}{|l|}{ Age (years) } \\
\hline$\geq 60$ & 62 & 29 & 33 & 0.658 & 0.417 \\
\hline$<60$ & 41 & 22 & 18 & & \\
\hline \multicolumn{6}{|l|}{ Pathological subtypes } \\
\hline Adenocarcinoma & 77 & 41 & 36 & & 0.334 \\
\hline Squamous cell carcinoma & 13 & 6 & 7 & & \\
\hline Adenosquamous carcinoma & 5 & 1 & 4 & & \\
\hline
\end{tabular}

ERCC1, excision repair cross complementing group 1 gene; NSCLC, non-small cell lung cancer.

Table II. Correlation between BRCA1 mRNA expression and the clinicopathological characteristics of patients with NSCLC.

\begin{tabular}{|c|c|c|c|c|c|}
\hline Clinicopathological parameters & No. cases & High expression & Low expression & $\chi^{2}$ & P-value \\
\hline \multicolumn{6}{|l|}{ Gender } \\
\hline Male & 36 & 20 & 16 & 1.244 & 0.265 \\
\hline Female & 20 & 8 & 12 & & \\
\hline \multicolumn{6}{|l|}{ Age (years) } \\
\hline$\geq 60$ & 36 & 19 & 17 & 0.311 & 0.577 \\
\hline$<60$ & 20 & 9 & 11 & & \\
\hline \multicolumn{6}{|l|}{ Pathological subtypes } \\
\hline Adenocarcinoma & 40 & 21 & 19 & & 0.025 \\
\hline Squamous cell carcinoma & 6 & 0 & 6 & & \\
\hline
\end{tabular}

BRCA1, breast cancer susceptibility 1 gene; NSCLC, non-small cell lung cancer.

Biosystems, Carlsbad, CA, USA). PCR reactions were performed using 2.5 $\mu \mathrm{l} \mathrm{SYBR-Green} \mathrm{Master} \mathrm{mix} \mathrm{(Applied}$ Biosystems), $0.25 \mu \mathrm{l}$ primer (20 pmol $/ \mu \mathrm{l}), 1 \mu \mathrm{l}$ DNA (25 ng/ $\mu \mathrm{l})$, and adding DEPC $\mathrm{H}_{2} \mathrm{O}$ to the total volume of $5 \mu \mathrm{l}$. Reaction without template was used as the negative control and $\beta$-actin as the endogenous control.

DNA extraction and direct sequencing for EGFR mutation status. Genomic DNA was isolated from 103 cases of paraffin-embedded NSCLC tissues using a tissue DNA kit (Omega Bio-Tek, Norcross, GA, USA), after obtaining written informed consent from the participants. The quality of DNA was determined by electrophoresis. Primers for EGFR were designed based on the sequence from NCBI GenBank and constructed by Sangon Biotech Co., Ltd., (Shanghai, China). PCR reactions $(20 \mu \mathrm{l})$ were performed as follows: 10X PCR buffer $2 \mu \mathrm{l}$, HotStar TaqDNA Polymerase (Qiagen) $0.25 \mu \mathrm{l}$, 5X Q-solution $4 \mu \mathrm{l}$, dNTP $2 \mu \mathrm{l}$, each Primer $1 \mu \mathrm{l}$, DNA template $1 \mu \mathrm{l}$ and distilled water $8.75 \mu \mathrm{l}$. Reactions without a template were used as the negative control. The PCR products were purified using an AxyPrep ${ }^{\mathrm{TM}}$ PCR clean-up kit (Axygen
Biosciences, Union City, CA, USA). A cycle sequencing reaction was performed using BigDye ${ }^{\circledR}$ Terminator v.3.1 Cycle Sequencing kit (Applied Biosystems) $0.8 \mu 1$, BigDye Sequence buffer $1.6 \mu 1$, forward/reverse primer $0.3 \mu \mathrm{l}$ and purified PCR product $1 \mu \mathrm{l}$, adding $\mathrm{dd}_{2} \mathrm{O}$ to $10 \mu \mathrm{l}$. The electrophoresis of the purified sequencing product was performed by the ABI 3100 capillary sequencer and the DNA sequence was analyzed by DNA Sequencing Analysis Software v.5.1 (Applied Biosystems).

Statistical analysis. mRNA expression was expressed as the mean \pm standard error of the mean (SEM). Pearson's $\chi^{2}$ or Fisher's exact test was used to examine the correlation between biological markers and clinicopathological characteristics. Pearson's correlation coefficient analysis was used to analyze the expression correlation. The Mann-Whitney $\mathrm{U}$ test was used to determine significant associations between gene expression and EGFR mutation status. A two tailed P-value $<0.05$ was considered as significant. The statistical analysis was performed by SPSS 13.0 software (SPSS, Inc., Chicago, IL, USA). 
Table III. Correlation between EGFR mutation status and the clinicopathological characteristics of patients with NSCLC.

\begin{tabular}{lccc}
\hline Clinicopathological characteristics & EGFR mutant & EGFR wild-type & Mutation rate (\%) \\
\hline Pathological subtypes & & & 0.462 \\
All & 27 & 76 & 26.2 \\
Adenocarcinoma & 24 & 53 & 31.2 \\
Squamous cell carcinoma & 2 & 11 & 15.4 \\
Adenosquamous carcinoma & 1 & 4 & 20.0 \\
Gender & & 54 & 12.90 \\
Male & 19 & 22 & 46.34 \\
Female & & & 0.001 \\
Age (years) & 19 & 41 & 31.67 \\
$\geq 60$ & 8 & 35 & 18.60 \\
$<60$ & & 57 \\
\hline
\end{tabular}

EGFR, epidermal growth factor receptor; NSCLC, non-small cell lung cancer.

Approval. The study was approved by the Ethics Committee of Nanjing University of Traditional Chinese Medicine (TCM), Nanjing, China. A statement of informed consent was signed by the participants.

\section{Results}

Pathological characteristics. The histological subtypes were: 77 adenocarcinomas, 5 adenosquamous carcinomas, 13 squamous cell carcinomas and 8 others. The slides were reviewed by two pathologists.

ERCC1 gene mRNA expression. ERCC1 gene expression levels were detected in specimens from 103 patients with NSCLC. The median ERCC1 expression value of 4.33 was set as the cut-off value (7), ERCC1 $\Delta \mathrm{Ct}<4.33$ was considered a low, while $\Delta \mathrm{Ct}>4.33$ was considered a high expression. ERCC1 expression was divided into several groups, based on the pathological classification. The results showed that ERCC1 gene expression was not associated with gender, age or histology (Table I).

BRCAl gene $m R N A$ expression. BRCA1 gene expression was detected among 56 cases. The median BRCA1 expression value of 6.88 was used as the cut-off value to define low/high mRNA expression. BRCA1 expression was divided into several groups, based on the pathological classification. As shown in Table II, the mRNA expression of BRCA1 was independent of gender or age, but associated with histology $(\mathrm{P}=0.025)$.

EGFR mutation status. EGFR mutation testing showed that: 27 in 103 (26.2\%) patients were EGFR mutant-type, of which 24 cases were adenocarcinoma $(24 / 77,31.2 \%)$ and 2 were squamous cell carcinoma $(2 / 13,15.4 \%)$ (Table III). The mutation rate of the adenocarcinoma was $31.2 \%$, which was slightly higher compared with other subtypes of NSCLC, although no statistically significant difference was evident. Results also showed that EGFR mutation was significantly higher in females $(19 / 41,46.34 \%)$ compared with males $(8 / 62,12.90 \%)$ $(\mathrm{P}=0.001)$. Mutations occurred mainly in exon 19 deletion
Table IV. Correlation between ERCC1, BRCA1 mRNA expression and EGFR mutation status.

\begin{tabular}{lcc}
\hline Expression levels & EGFR mutant & EGFR wild-type \\
\hline ERCC1 high & 10 & 41 \\
ERCC1 low & 17 & 35 \\
BRCA1 high & 2 & 20 \\
BRCA1 low & 8 & 26 \\
\hline
\end{tabular}

ERCC1, excision repair cross complementing group 1 gene; BRCA1, breast cancer susceptibility 1 gene; EGFR, epidermal growth factor receptor.

(E19del) and exon 21 L858R mutation, accounting for $85.2 \%$ $(23 / 27)$ of the total mutations.

ERCC1, BRCA1 mRNA expression and EGFR mutation. A positive correlation was found between ERCC1 and BRCA1 mRNA expression ( $\mathrm{r}=0.318, \mathrm{P}=0.017)$. Of 27 EGFR mutant-type NSCLC, a high ERCC1 gene expression was detected in 10 cases $(37.0 \%)$, while a low expression was found in 17 cases $(63.0 \%)$. Of 10 EGFR mutant-type NSCLC, a high BRCA1 gene expression was detected in 2 cases $(20.0 \%)$, while a low BRCA1 expression was found in 8 cases $(80.0 \%)$. As shown in Table IV, the EGFR mutant-type was more likely to be categorized as ERCC1-low $(\mathrm{P}=0.313)$ and BRCA1-low $(\mathrm{P}=0.018)$, while the association of EGFR mutation and BRCA1 expression reached statistically significant levels.

Clinical outcome based on biological markers. The follow-up result showed that one-year survival was 82.6, 76.2 and 84.6\% in the low ERCC1, low BRCA1 and EGFR mutant groups, respectively vs. 76.3, 80.0 and $71.7 \%$ in the high ERCC1, high BRCA1 and EGFR wild-type groups, respectively. No difference was detected in the one-year survival rate, based on either 
ERCC1, BRCA1 mRNA expression levels or EGFR mutation status $(\mathrm{P}>0.05)$.

\section{Discussion}

Predictive biomarkers were used to select suitable patients for molecular-targeted therapy to improve the outcome. Several biomarkers including ERCC1, BRCA1, RRM1 and EGFR have been characterized in retrospective analyses of individualized therapy. The ERCC1 gene encodes a protein with a nucleotide excision repair (NER), an important member in NER systems (8). Previous studies have shown that patients with a low ERCC1 expression are likely to benefit from platinum-based chemotherapy, whereas this is not the case for patients with a high expression, suggesting that ERCC1 may be a predictor of chemotherapy efficacy (9). The association between ERCC1 expression and patient demographics has also been examined, with conflicting results $(6,10,11)$. Such results may be explained by differences in trial design and methods. In this study, ERCC1 expression was detected in the paraffin-embedded NSCLC tissues and findings showed that this expression was not associated with histology, gender and age.

BRCA1 is important in multiple DNA damage repair pathways and is considered to be a differential modulator of survival with cisplatin and paclitaxel (12-14). Decreased BRCA1 mRNA expression enhances cisplatin sensitivity but leads to resistance to antimicrotubule agent such as paclitaxel. To examine the distribution of BRCA1 expression in NSCLC, we quantified BRCA1 mRNA levels in 56 specimens with NSCLC. The results show that the mRNA is expression of BRCA1 was independent of gender and age but is associated with histology and ERCC1 expression. The positive correlation between ERCC1 and BRCA1 expression suggests that a high intratumoral BRCA1 expression is accompanied by an elevated ERCC1 expression, which may be explained by the fact that ERCC1 and BRCA1 are both involved in the pathway of NER to repair DNA adducts.

EGFR, whose overexpression and/or mutation is able to control tumor growth through the signal transduction pathway, has become a potent target gene for tumor therapy (15). However, EGFR-targeted drugs, such as TKI had no significant effect on patients without EGFR mutations (16). Studies have found that the EGFR mutation rate was $~ 33 \%$ in the Asian population and that EGFR mutant-type patients benefited from platinum chemotherapy $(17,18)$. In the present study, 103 patients with NSCLC were examined for EGFR mutations. Results show a total of 27 cases $(26.2 \%)$ had EGFR mutations, consistent with previous reports $(17,18)$. Mutations occur mainly in E19del and exon 21 L858R mutation, accounting for $85.2 \%$ (23/27) of the total mutations. Of the 27 mutations, 13 cases of E19del were female. In addition, EGFR mutations are more likely to occur in females, especially for E19del.

IPASS and other studies have shown patients with EGFR mutations to be more sensitive to platinum-based chemotherapy in NSCLC (19-21). EGFR and DNA repair pathways have been linked in preclinical studies, possibly through BRCA1, with implications for platinum-based therapy (22-24). A multi-center trial has shown that EGFR mutation was highly associated with a low mRNA expression level of ERCC1 in NSCLC (6). In this study, the results show that in EGFR mutant patients ERCC1 and BRCA1 were more likely to exhibit a low expression (63.0 and 80.0\%, respectively), although the first was not statistically significant, which may be due to the relatively small patient population or ethnic differences.

Certain studies suggest that a high ERCC1 and BRCA1 mRNA expression is correlated with poor survival in NSCLC $(25,26)$. In the present study, due to the short follow-up period, available data are limited regarding the long-term survival of patients. As yet, none of these three markers are potential independent prognostic factors for clinical outcome in NSCLC.

In summary, the correlation between EGFR mutations, ERCC1 and BRCA1 expression in NSCLC was investigated, and a trend for a low expression of ERCC1 and BRCA1 in EGFR mutant patients was detected, possibly accounting for the high sensitivity of platinum-based chemotherapy in NSCLC. In addition, data on biomarkers showed controversial results in different laboratories, therefore, laboratory tests assessing biomarkers need to be standardized.

\section{Acknowledgements}

The authors would like to thank Yi Sun, Jie Chen and Yanying Zhen for their laboratory support and secretarial assistance. This study was funded by the Priority Academic Program Development of the Jiangsu Higher Education Institutions (PAPD).

\section{References}

1. Simon GR, Sharma S, Cantor A, et al: ERCC 1 expression is a predictor of survival in resected patients with non-small cell lung cancer. Chest 127: 978-983, 2005.

2. Cobo M, Isla D, Massuti B, et al: Customizing cisplatin based on quantitative excision repair cross-complementing $1 \mathrm{mRNA}$ expression: a phase III trial in non-small cell lung cancer. J Clin Oncol 25: 2747-2754, 2007.

3. Quinn JE, Kennedy RD, Mullan PB, Gilmore PM, Carty M, Johnston PG and Harkin DP: BRCA1 functions as a differential modulator of chemotherapy-induced apoptosis. Cancer Res 63: 6221-6228, 2003

4. Taron M, Rosell R, Felip E, Mendez P, Souglakos J, Ronco MS, Queralt C, Majo J, Sanchez JM, Sanchez JJ and Maestre J: BRCA1 mRNA expression levels as an indicator of chemoresistance in lung cancer. Hum Mol Genet 13: 2443-2449, 2004.

5. Hotta K, Kiura K, Toyooka S, et al: Clinical significance of epidermal growth factor receptor gene mutations on treatment outcome after first-line cytotoxic chemotherapy in Japanese patients with non-small cell lung cancer. J Thorac Oncol 2: 632-637, 2007.

6. Gandara DR, Grimminger P, Mack PC, et al: Association of epidermal growth factor receptor activating mutations with low ERCC1 gene expression in non-small cell lung cancer. J Thorac Oncol 5: 1933-1938, 2010.

7. Tian SW, Li H, Xie L, et al: The associated analysis of ERCC1 gene polymorphism in regulatory region and mRNA Q-PCR expression. Chin Clin Oncol 12: 1073-1076, 2009.

8. Reed E: ERCC1 and clinical resistance to platinum-based therapy. Clin Cancer Res 11: 6100-6102, 2005.

9. Rosell R, Danenberg KD, Alberola V, et al: Ribonucleotide reductase messenger RNA expression and survival in gemcitabine/cisplatin-treated advanced non-small cell lung cancer patients. Clin Cancer Res 10: 1318-1325, 2004.

10. Lord RV, Brabender J, Gandara D, et al: Low ERCC1 expression correlates with prolonged survival after cisplatin plus gemcitabine chemotherapy in non-small cell lung cancer. Clin Cancer Res 8: 2286-2291, 2002.

11. Shan L, Han ZG, Liu L, et al: ERCC1 and BRCA1 expressions in advanced non-small cell lung cancer and their relationship with cisplatin resistance. Tumor 29: 571-574, 2009 (In Chinese). 
12. Rosell R, Cecere F, Santarpia M, et al: Predicting the outcome of chemotherapy for lung cancer. Curr Opin Pharmacol 6: 323-331, 2006.

13. Mullan PB, Quinn JE and Harkin DP: The role of BRCA1 in transcriptional regulation and cell cycle control. Oncogene 25: 5854-5863, 2006.

14. Kennedy RD, Quinn JE, Mullan PB, et al: The role of BRCA1 in the cellular response to chemotherapy. J Natl Cancer Inst 96 : 1659-1668, 2004.

15. Jorissen RN, Walker F, Pouliot N, et al: Epidermal growth factor receptor: mechanisms of activation and signaling. Exp Cell Res 284: 31-53, 2003

16. Mok TS, Wu YL, Thongprasert S, et al: Gefitinib or carboplatin-paclitaxel in pulmonary adenocarcinoma. N Engl J Med 361: 947-957, 2009

17. Wang JR, Zhang SP, Lai RS, et al: Intron 1 (CA) n dinucleotide repeat polymorphism and mutations of epidermal growth factor receptor and responsiveness of molecular targeted therapy in lung cancer. Mod Pathol 17: 2113-2117, 2009.

18. Lynch TJ, Bell DW, Sordella R, et al: Activating mutations in the epidermal growth factor receptor underlying responsiveness of non-small cell lung cancer to gefitinib. N Engl J Med 350: 2129-2139, 2004

19. Bell DW, Lynch TJ, Haserlat SM, et al: Epidermal growth factor receptor mutations and gene amplification in non-small cell lung cancer: molecular analysis of the IDEAL/INTACT gefitinib trials. J Clin Oncol 23: 8081-8092, 2005.
20. Wu JU, Yub CJ, Shih JY, et al: Influence of first-line chemotherapy and EGFR mutations on second-line gefitinib in advanced non-small cell lung cancer. Lung Cancer 67: 348-354, 2010.

21. Wu JY, Shih JY, Yang CH, et al: Second-line treatments after first-line gefitinib therapy in advanced non-small cell lung cancer. Int J Cancer 126: 247-255, 2010.

22. Li L, Wang H, Yang ES, et al: Erlotinib attenuates homologous recombinational repair of chromosomal breaks in human breast cancer cells. Cancer Res 68: 9141-9146, 2008.

23. Bandyopadhyay D, Mandal M, Adam L, et al: Physical interaction between epidermal growth factor receptor and DNA-dependent protein kinase in mammalian cells. J Biol Chem 273: 1568-1573, 1998.

24. Rosell R, Perez-Roca L, Sanchez JJ, et al: Customized treatment in non-small cell lung cancer based on EGFR mutations and BRCA1 mRNA expression. PLoS One 4: e5133, 2009.

25. Rosell R, Tarón M and O'Brate A: Predictive molecular markers in non-small cell lung cancer. Curr Opin Oncol 13: 101-109, 2001.

26. Taron M, Rosell R, Felip E, et al: BRCA1 mRNA expression levels as an indicator of chemoresistance in lung cancer. Hum Mol Genet 13: 2443-2449, 2004. 